\title{
Biocrusts: the living skin of the earth
}

\author{
Matthew A. Bowker (D) Sasha C. Reed • \\ Fernando T. Maestre $\cdot$ David J. Eldridge
}

Received: 14 June 2018 / Accepted: 22 June 2018 / Published online: 3 July 2018

(C) This is a U.S. Government work and not under copyright protection in the US; foreign copyright protection may apply 2018

\section{Introduction}

Biological soil crusts (biocrusts) form a "living skin" at the soil surface in many low-productivity ecosystems around the world including water- and cold-limited environments, and early-successional seres (Belnap et al. 2003). They may be composed of any configuration of soil surfacedwelling cyanobacteria, eukaryotic algae, lichens, mosses or liverworts, and support assemblages of decomposers and a faunal food web (Belnap et al. 2003). These soil surface communities have global relevance, as it has been recently estimated that they cover about $12 \%$ of the terrestrial surface currently (Rodríguez-Caballero et al. 2018). Biocrust communities are perhaps an ideal subject for the

Responsible Editor: Hans Lambers.

M. A. Bowker $(\square)$

School of Forestry, Northern Arizona University, 200 E. Pine

Knoll Dr., Box 15018, Flagstaff, AZ 86011, USA

e-mail: matthew.bowker@nau.edu

\section{S. C. Reed}

Southwest Biological Science Center, US Geological Survey, 2290 S. West Resource Blvd., Moab, UT 84532, USA

\section{F. T. Maestre}

Departamento de Biología y Geología, Física y Química Inorgánica, ESCET, Universidad Rey Juan Carlos, c/ Tulipán s/n, 28933 Móstoles, Spain

\section{J. Eldridge}

Centre for Ecosystem Science, School of Biological, Earth and Environmental Sciences, University of New South Wales, Sydney, NSW 2052, Australia journal Plant and Soil, as they are simultaneously plantlike, due to their dominance by photoautotrophs, yet biocrusts are also clearly a physical feature of the soil given that component organisms are enmeshed in, adherent to, or otherwise in direct contact with the soil surface. The activity of the organisms is what engineers the wellaggregated thin layer at the soil surface that we recognize as a biocrust (Belnap et al. 2003). The contributions of biocrusts to ecosystem function has fueled much research interest, initially based on the observation of biocrusts' soil aggregating and erosion-resisting nature. More recently biocrusts have been identified as a multifunctional, globally-relevant ecosystem element instrumental in: 1 . building or otherwise altering soil nutrient stocks through $\mathrm{N}$-fixation (Elbert et al. 2012), dust trapping (Reynolds et al. 2001) and nutrient cycling (Strauss et al. 2012), 2. influencing hydrological properties of soil such as the water balance (Chamizo et al. 2016), and 3. the thermal energy balance of the ecosystem (Coradeau et al. 2016; Rutherford et al. 2017).

Biocrust science was sparse before the 1970s, as evidenced by few publications and little recognition of the concept; however, a series of key events in the biocrust research community has brought biocrusts from a niche interest into the mainstream. First, the initial publication in 2001 of an edited volume (Belnap and Lange 2003) served to bring together disparate threads floristic, biogeographical, physiological, functional, applied - of biocrust research through an ecological lens. One effect of this publication was to demonstrate that biocrusts were a global phenomenon, and hasten the internationalization of the field from a handful of 
research centers to the global community which exists today. A marked increase in the number of biocrust papers per year followed the publication of this book; publication rates in recent years are approaching an order of magnitude greater than rates in 2000 (Weber et al. 2016). The second edited volume, focused on synthesizing the flurry of research that followed the first book (Weber et al. 2016), was recently published and we fully expect it to continue stimulating and guiding research on biocrusts globally.

Another key event in the development of biocrust research was the establishment, sustenance, and growth of a triennial international biocrust meeting. The 3rd International Workshop on Biological Soil Crusts (also known as Biocrust 3), was held in Moab, Utah from September 26-30 of 2016, following conferences in Zellingen-Retzbach (Germany) in 2010 and Madrid (Spain) in 2013 (Sancho et al. 2014). Biocrust 3 was the largest yet of the series, featuring over 100 papers presented, and about 150 attendees from 21 different nations. Research was presented from all seven continents. We view the success of this conference series as a milestone event in the development of our identity as a research community and a force spurring our future research directions (Ferrenberg and Reed 2017). As the science matures, novel and sophisticated research lines are emerging which: 1. Infuse knowledge and tools from multiple fields including soil science, biochemistry, microbial ecology and -omics fields to provide a deeper understanding of how biocrusts perform their myriad ecosystem functions. 2. Probe the ways that biocrusts influence, shape and directly interact with plant, animal and microbial communities, 3. Identify and quantify traits of biocrust organisms that have functional relevance, and 4. Apply this and other knowledge to restore or rehabilitate degraded ecosystems. The collection of papers in this special issue, which we describe below, primarily derive from Biocrust 3, and are a good sample of the most recent and exciting biocrust research that is being carried out all around the world.

\section{New insights into how biocrusts impact ecosystem functioning}

The community of autotrophs and heterotrophs that make up biocrusts stabilize soils, dictate soil carbon and nutrient cycling, and help determine the fate of precipitation. Our understanding of how biocrusts regulate core ecosystem functions continues to grow, and multiple papers in this special issue highlight the complexity of linkages between the structure and function of biocrusts and ecosystem processes. The ability of biocrusts to stabilize soils has long been known, and this function offers numerous important opportunities for understanding and managing dryland landscapes. Felde et al. (2018) explored pedological mechanisms that drive biocrusts' capacity to stabilize soil in the Negev Desert, measuring penetration resistance and cementing agents and their relationships with a suite of soil characteristics. This analysis highlighted the importance of soil texture and offered suggestions for modifying soil characteristics in ways that may improve biocrusts' capacity for stabilizing soils. Rossi et al. (2018) explored another mechanism through which biocrusts are believed to increase soil stability: the extracellular polymeric matrix (EPM). Through a review of the literature they show that the EPM can be placed into the context of three fractions, one water soluble, one more adherent to cells and sediments, and one firmly attached to microbial cells. These fractions play important roles in sediment cohesion and resistance to erosion. The classification and extraction methods they present offer a means to improve our understanding of how biocrusts stabilize soil.

In addition to soil stabilization, biocrusts affect the cycling of carbon and nutrients, as well as the microbial communities living atop, around, and beneath them. Benavent-González et al. (2018) showed that plant and biocrust identity were associated with different levels of soil functioning and microbial abundance in Antarctica. In particular, the activity of multiple enzymes varied by species and the authors observed positive correlations between soil nutrient availability and microbial abundance with biocrusts compared with bare soil. These results are of interest not only because of the implications for species' effects on numerous soil properties, but also because they suggest that factors inducing change in the spatial distribution of these species (e.g., climate change) could result in altered functioning of Antarctic ecosystems.

The linkages between biocrust communities and ecosystem functioning also offer opportunity for the development and use of innovative new tools and approaches for understanding biocrusts and their functions. For example, Swenson et al. (2018) describe a new set of methods based on state-of-the art metabolomic approaches for investigating metabolite sorption on biocrusts, and used these methods to show that biocrusts sorb more metabolites than underlying soil. The results not only paint an interesting picture of 
biocrusts as a passive nutrient filter - sorbing the resources of microbes released during wetting events - but also propose additional pathways through which biocrusts acquire resources.

\section{Biocrusts: soil media influencers?}

Interactions arising between biocrust constituents and vascular plants have received increased interest in recent years (see Zhang et al. 2016 for a review). A growing body of literature indicates that biocrusts can influence the germination of vascular plant seeds (e.g., Su et al. 2009), and several papers in this issue explore these interactions. Ferrenberg et al. (2018) use a greenhouse study to evaluate how biocrusts and warming affect the germination and subsequent growth of Bromus tectorum, an invasive grass in western North America. They found that biocrusts promoted the growth and nutrient contents of $B$. tectorum, likely by increasing soil fertility. Biocrusts also interacted with seed treatment-provenance to affect germination. The authors discuss the implications of these findings, the importance of teasing apart physical and chemical controls over plant germination, and the dynamics of invasion by $B$. tectorum in a warmer world. MuñozRojas et al. (2018) show that bio-priming of shrub seeds with Microcoleus and Nostoc spp. has the potential to enhance soil functionality in mine-waste soil by increasing the survival of Australian native plants that fix substantial amounts of nitrogen. These findings add to the still scarce literature on the effects of cyanobacteria on the regeneration of native species, and have implications to improve actions aiming at enhancing the establishment of these species during the restoration of post-mining landscapes.

The role of biocrusts in the nutrient status of vascular plants was explored by Jayne Belnap and collaborators more than 25 years ago (e.g., Belnap and Harper 1995). This research has become more mechanistic in the last decade, and it has been hypothesized that plant and biocrust patches are functionally integrated by exchanges of carbon and nitrogen through a symbiotic fungal network (Green et al. 2008). DettweilerRobinson (2018) uses field observations and stable isotope techniques to explore whether biocrusts can use plant-derived carbon. Overall, her findings did not provide evidence to support functional coupling in carbon cycling between biocrusts and vascular plants. However, the study raises raise multiple testable, alternative hypotheses about the mechanisms underlying these results, which will guide future research on this important topic in plant-biocrust interactions.

In recent years, technological advances have allowed an exponential increase in the number of studies characterizing microbial communities in biocrusts using nucleic acid-based approaches (e.g., Steven et al. 2015; Delgado-Baquerizo et al. 2018). Chilton et al. (2018) addresses a very poorly studied aspect of this interaction; how biocrust morphology, which is linked to ecosystem functioning (Eldridge and Rosentreter 1999), affects microbial communities associated with biocrusts. They found that readily discernible biocrust features, such as color, shape and thickness, are related to the composition and structure of soil microbial communities. They found marked differences in the microbial signatures among developmental stages, with network analyses indicating highly-connected hubs indicative of small networks. This molecular approach to joining morphological and genetic perspectives suggested that readily discernible biocrust features could be valuable indicators of microbial composition. These findings have implications for managers aiming to use biocrusts as indicators of ecosystem health and functioning which are discussed in the article.

Despite being a prevalent component of many terrestrial ecosystems, and particularly of drylands, the interactions of biocrusts with other organisms have traditionally been neglected, particularly when compared with other biotic components such as vascular plants or soil animals (Whitford 2002). Fortunately this has changed in recent years, and biocrust researchers are now tackling the complexity of interactions in which their constituent organisms are involved (Bowker 2007; Lindo and Gonzalez 2010). The different papers on biotic interactions involving biocrusts included in this special issue highlight the importance of considering these organisms to fully understand the complexity of the web of life and how the interactions among the different taxa shape key questions that are of interest for scientists and managers alike such as ecosystem responses to global change drivers and the management of invasive species.

\section{The emergence of trait-based biocrust ecology}

Functional traits are qualitative or quantitative elements of the phenotype of an organism, including descriptors of morphology, anatomy, biochemistry, phenology or 
physiology. Functional traits belong to two major groups (Lavorel and Garnier 2002). Response traits are those which indicate how an organism might respond to an environmental stimulus. Effect traits are those which indicate the ways in which a species is likely to influence its environment and other species. The rapid emergence and exponential growth of trait-based ecology in the past two decades has had resounding impacts in plant ecology in areas ranging from community assembly and coexistence theory (Kraft et al. 2015) to the determination of ecosystem multifunctionality (Gross et al. 2017). Underlying the growth of trait-based approaches was the concerted effort to create databases of plant functional traits, some of them global (Kattge et al. 2011).

Biocrusts are strong candidates for a trait-based (as opposed to species-based) approach, because taxonomic knowledge is incomplete, and taxonomic expertise is both sparse and usually confined to one or a few groups of organisms that compose biocrusts. Nevertheless, to date, no functional trait database exists for biological soil crusts despite evidence that different species may have unique combinations of effects on their environment (Bowker et al. 2011). Recent research is laying the groundwork for the development of protocols for the measurement of key functional traits specific to biocrusts (Mallen-Cooper and Eldridge 2016).

Five papers in this special issue contribute to the effort to identify the most informative functional traits in biocrusts, and understand variation in these functional traits both within and among species. One common theme that emerges are fundamental differences between mosses and lichens, and between cyanolichens and chlorolichens. Torres-Cruz et al. (2018) measures nitrogen fixation rates and tissue nitrogen concentration in four co-occurring lichen species, finding that biocrusts dominated by all four species fix some nitrogen, but that cyanolichen-dominated biocrusts likely contribute the most to ecosystem nitrogen stocks. Given that $\mathrm{N}$-fixation is among the most touted of biocrust effect traits, it is surprising that so few species-level rates are available. Tamm et al. (2018) develop response curves of $\mathrm{CO}_{2}$ exchange as a function of moisture, light and temperature gradients. These authors find that organisms tend to be similar across broad taxonomic groups, for example cyanobacteria and cyanolichen biocrusts exhibit lower moisture optima, higher temperature optima, and higher light saturation points, but moss biocrusts are opposite in all of these response traits. These response traits may be predictive of how biocrusts might respond to climate change.

Although broad taxonomic groups do appear to summarize considerable functional differences among species, other research highlights the influence of the environment, and the variation within species. Raggio et al. (2018) shed some light on the environmental influence on variation in the gas exchange capacity, a key functional trait, of moss- and lichen-dominated biocrusts; extremely divergent environments appear to override some of the distinctions between lichens and mosses and influence trait variation within a species. Finally, observing tissue $\mathrm{N}$ and $\mathrm{C}, \delta^{13} \mathrm{C}$ and $\delta{ }^{15} \mathrm{C}$, ConcostrinaZubiri et al. (2018) also observe, first and foremost, a clear distinction between most moss species and most lichens. However, almost as influential are environmental variables related to climate and edaphic properties, which appear to drive cross-site trait variability, perhaps in confirmation of the findings of Raggio et al. (2018).

Mallen-Cooper et al. (2018) put in practice a functional traits approach focusing on effect traits to compute functional diversity of naturally occurring biocrusts along climatic and disturbance gradients in Australia. They find that increasing aridity, a footprint of climate change in global drylands (Huang et al. 2016), has a significant direct negative effect on biocrust functional diversity. The effects of multiple grazers (livestock, kangaroos and rabbits) on biocrust functional diversity are predominantly indirect and negative. Their findings provide novel evidence regarding the likely impacts of increasing aridity and intensified livestock grazing, two major components of ongoing global change, will reduce the functional diversity of biocrust communities and associated ecosystem functions.

In summary, this collection of papers demonstrates a clear utility of developing functional trait protocols for biocrust organisms, and creating biocrust-specific trait databases. With these tools in hand, we will enhance our ability to more easily detect important changes in biocrust community structure, and biocrust-mediated ecosystem multifunctionality.

\section{A new era of biocrust restoration activity}

The contribution of biocrusts to ecosystem function in their habitats makes them an intriguing and promising potential ecological restoration tool (Bowker 2007). Over the past decade especially there has been a surge 
in the development of technologies to restore biocrust communities across global drylands, sometimes translating into field success (Lan et al. 2014; Chiquoine et al. 2016). Methods for culturing biocrust species have proliferated and diversified (e.g., Maestre et al. 2006; Antoninka et al. 2015; Ayuso Velasco et al. 2016). However, to achieve effective restoration under field conditions, the significant hurdle of field establishment must be overcome. Possible solutions include selection of appropriate taxa or genetic source material, amelioration of stressful conditions during the establishment phase, and development of appropriate delivery mechanisms. Five manuscripts in this special issue address the subject of reestablishment of biocrusts in the USA, China and Australia.

Using the desert moss Syntrichia ruralis, which is common across northern hemisphere drylands, Doherty et al. (2018) show that mosses can readily be grown under glasshouse conditions on a soil medium. Similarly, sterile soil can be inoculated with cyanobacteria under laboratory conditions, and subsequently expand (Sorochkina et al. 2018). Doherty et al. (2018) also demonstrate that different source populations of biocrust organisms exhibit different growth and stress tolerance traits, which may be highly relevant to their development and deployment as restoration materials.

In addition to these papers exploring the active restoration of biocrusts, the study of Zhang et al. (2018) also has implications for using biocrusts during restoration activities. These authors explore how biocrustforming cyanobacterial and algal communities change with biocrust development after a landslide in the Loess Plateau (China). The biocrusts studied were dominated by Phormidium tenue (Cyanophyta) regardless of biocrust age, while the dominance of Oscillatoria sp. (Cyanophyta) increased with biocrust age and was positively correlated with the accumulation of carbon, nitrogen and phosphorus in the topsoil. These findings suggest that species such as Phormidium tenue can be used for rapid biocrust formation, and that species such as Oscillatoria sp. can promote carbon fixation and nutrient accumulation, thereby accelerating biocrusts into a later successional stage.

Antoninka et al. (2018) show that both moss and cyanobacterial crusts can be established under field conditions, but that the response depends on the nature of the source crust propagules, with fieldsalvaged biocrusts producing greater species richness and biomass in application plots than those grown in the glasshouse. This result is likely related to the hardened nature of field-conditioned natural biocrusts, a state that thus far has been challenging to induce in indoor-culture biocrusts. Successful, field-based re-establishment of biocrusts will likely also vary greatly depending on environmental conditions, some of which could plausibly be ameliorated. For example, Bu et al. (2018) show that the establishment of moss crusts under field conditions depended on soil nutrients and level of shade, as well as the season in which the crusts were inoculated. Clearly a major challenge for biocrust researchers is to identify the optimal conditions under which they can be re-established, as well as selecting the appropriate species and source populations that are adapted to specific environmental conditions.

We have come a long way since early attempts to reestablish soil crusts by translocating crushed crust material (Belnap 1993) or applying soil slurries (St. Clair et al. 1986; Scarlett 1994) to disturbed areas (Bowker 2007), generally moving towards an intensive research effort based on ex-situ culture of the organisms. The collection of papers on restoration in this special issue highlights the directions in which the 'art' of restoration of soil crusts has evolved over the past decade, and how we are beginning to move 'beyond the laboratory' and into the field, with great potential for practical, landbased restoration programs.

\section{Conclusion}

The papers included in this special issue are necessarily an incomplete picture of the wide range of topics presented at Biocrust 3 or being studied by the biocrust research community. Additional papers presented at this conference were reviewed by Ferrenberg and Reed (2017), and still others focusing on the impacts of climate change on biocrusts and their functional roles on biogeochemical cycling are appearing in upcoming special issues in New Phytologist and Biogeosciences. Nonetheless, this collection offers a sample of some of the most engaging emerging themes in biocrust science, and a possible foundation for the next generation of researchers to build upon. We look forward to continued growth, cross-pollination of ideas, and diversification of our fields at Biocrust 4, to be held in Queensland, Australia in 2019. 
Acknowledgements The Biocrust 3 conference was supported by contributions from Northern Arizona University (School of Forestry, Merriam-Powell Center for Environmental Research, College of Engineering, Forestry and Natural Sciences, Office of the Provost, Office of the Vice President for Research, School of Earth Sciences and Environmental Sustainability), the US Geological Survey, Brigham Young University (Charles Redd Center for Western Studies, Monte L. Bean Life Sciences Museum), the Nature Conservancy's Canyonlands Research Center, the Soil Ecological Society, Northwest Lichenologists, the New Phytologist Trust, and Walz - Bay Instruments. Lara Schmit was instrumental in conference planning and logistics. Steve Fick provided helpful editorial comments on early drafts. We would also like to thank all attendees of Biocrust 3, and the contributors of papers to this special issue. Finally we thank all of the reviewers and Dr. Hans Lambers, the Editor-in-chief, and his team at PLSO for facilitating this special issue. Any use of trade, firm, or product names is for descriptive purposes only and does not imply endorsement by the U.S. Government.

\section{References}

Antoninka AJ, Bowker MA, Reed SC, Doherty K (2015) Production of greenhouse-grown biocrust mosses and associated cyanobacteria to rehabilitate dryland soil function. Restor Ecol 24:324-335

Antoninka A, Bowker MA, Chuckran P, Barger NN, Reed S, Belnap J (2018) Maximizing establishment and survivorship of field-collected and greenhouse-cultivated biocrusts in a semi-cold desert. Plant Soil. https://doi.org/10.1007/s11104017-3300-3 (this issue)

Ayuso Velasco S, Giraldo Silva A, Nelson CJ, Barger NN, GarciaPichel F (2016) Microbial nursery production of high-quality biological soil crust biomass for restoration of degraded dryland soils. Appl Environ Microbiol 83:e02179-e02116

Belnap J (1993) Recovery rates of cryptobiotic crusts: inoculant use and assessment methods. Great Bas Nat 53:89-95

Belnap J, Harper KT (1995) Influence of cryptobiotic soil crusts on elemental content of tissue of two desert seed plants. Arid Soil Res Rehab 9:107-115

Belnap J, Lange OL (eds) (2003) Biological soil crusts: structure, function and management. Ecological Studies 150, Springer, Berlin

Belnap J, Büdel B, Lange OL (2003) Biological soil crusts: characteristics and distribution. In: Belnap J, Lange OL (eds) Biological soil crusts: structure, function and management. Ecological Studies 150, Springer, Berlin, pp 3-30

Benavent-González A, Delgado-Baquerizo M, Fernández-Brun L, Singh BK, Maestre FT, Sancho LG (2018) Identity of plant, lichen and moss species connects with microbial abundance and soil functioning in Maritime Antarctica. Plant Soil DOI TBD (this issue)

Bowker MA (2007) Biological soil crust rehabilitation in theory and practice: an underexploited opportunity. Restor Ecol 15: $13-23$

Bowker MA, Mau RL, Maestre FT, Escolar C, Castillo-Monroy A (2011) Functional profiles reveal unique ecological roles of various biological soil crust organisms. Func Ecol 25:787-795
Bu C, Li R, Wang C, Bowker MA (2018) Successful field cultivation of moss biocrusts on disturbed soil surfaces in the short term. Plant Soil. https://doi.org/10.1007/s11104-0173453-0 (this issue)

Chamizo S, Cantón Y, Rodríguez-Caballero E, Domingo F (2016) Biocrusts positively affect the soil water balance in semiarid ecosystems. Ecohydrology 9:1208-1221

Chilton AM, Neilan BA, Eldridge DJ (2018) Biocrust morphology is linked to marked differences in microbial community composition. Plant Soil. https://doi.org/10.1007/s11104017-3442-3 (this issue)

Chiquoine LP, Abella SR, Bowker MA (2016) Rapidly restoring biological soil crusts and ecosystem functions in a severely disturbed desert ecosystem. Ecol Appl 26:1260-1272

Concostrina-Zubiri L, Matos P, Giordani P, Branquinho C (2018) Biocrust tissue traits as potential indicators of global change in the Mediterranean. Plant Soil. https://doi.org/10.1007 /s11104-017-3483-7

Coradeau E, Karaoz U, Lim HC, Nunes da Rocha U, Northen T, Eoin B, Garcia-Pichel F (2016) Bacteria increase arid-land soil surface temperature through the production of sunscreens. Nature Communications 7:10373

Delgado-Baquerizo M, Maestre FT, Eldridge DJ, Bowker MA, Jeffries T, Singh BK (2018) Biocrust-forming mosses mitigate the impact of aridity on soil microbial communities in drylands: observational evidence from three continents. New Phytol. https://doi.org/10.1111/nph. 15120

Dettweiler-Robinson E (2018) Biocrust carbon isotope signature was depleted under a C3 forb compared to interspace. Plant Soil. https://doi.org/10.1007/s11104-017-3558-5

Doherty KL, Bowker MA, Antoninka AJ (2018) Biocrust moss populations differ in growth rates, stress response, and microbial associates. Plant Soil. https://doi.org/10.1007/s11104017-3389-4 (this issue)

Elbert W, Weber B, Burrows S, Steinkamp J, Büdel B, Andreae MO, Pöschl U (2012) Contribution of cryptogamic covers to global cycles of carbon and nitrogen. Nat Geosci 5: 459-462

Eldridge DJ, Rosentreter R (1999) Morphological groups: a framework for monitoring microphytic crusts in arid landscapes. $\mathrm{J}$ Arid Environ 41:11-25

Felde VJMNL, Chamizo S, Felix-Hemmingsen P, Drahorad SL (2018) What stabilizes biological soil crusts in the Negev Desert? Plant Soil. https://doi.org/10.1007/s11104-0173459-7 (this issue)

Ferrenberg S, Reed SC (2017) Biocrust ecology: unifying microand macro-scales to confront global change. New Phytol 216: 643-646

Ferrenberg S, Faist AM, Howell A, Reed SC (2018) Biocrusts enhance soil fertility and Bromus tectorum growth, and interact with warming to influence germination. Plant Soil. https://doi.org/10.1007/s11104-017-3525-1 (this issue)

Green LE, Porras-Alfaro A, Sinsabaugh RL (2008) Translocation of nitrogen and carbon integrates biotic crust and grass production in desert grassland. J Ecol 96:1076-1085

Gross N, le Bagousse-Pinguet Y, Liancourt P, Berdugo M, Gotelli NJ, Maestre FT (2017) Functional trait diversity maximizes ecosystem multifunctionality. Nat Ecol Evol 1:0132

Huang J, Yu H, Guan X, Wang G, Guo R (2016) Accelerated dryland expansion under climate change. Nat Clim Change $6: 166-171$ 
Kattge J, Díaz S, Lavorel S, Prentice IC, Leadley P, Bönisch G, Garnier E, Westoby M, Reich PB, Wright IJ, Cornelissen JHC, Violle C, Harrison SP et al (2011) TRY - a global database of plant traits. Global Change Biol 17:2905-2935

Kraft NJB, Godoy O, Levine JM (2015) Plant functional traits and the multidimensional nature of species coexistence. Proc Nat Acad Sci 112:797-802

Lan S, Zhang Q, Wu L, Liu Y, Zhang D, Hu C (2014) Artificially accelerating the reversal of desertification: cyanobacterial inoculation facilitates the succession of vegetation communities. Environ Sci Technol 48:307-315

Lavorel S, Garnier E (2002) Predicting changes in community composition and ecosystem functioning from plant traits: revisiting the Holy Grail. Func Ecol 16:545-556

Lindo Z, Gonzalez A (2010) The bryosphere: an integral and influential component of the Earth's biosphere. Ecosystems 13:612-627

Maestre FT, Martín N, Díez B, Lopez-Poma R, Santos F, Luque I, Cortina J (2006) Watering, fertilization, and slurry inoculation promote recovery of biological crust function in degraded soils. Microbial Ecol 52:365-377

Mallen-Cooper M, Eldridge DJ (2016) Laboratory-based techniques for assessing the functional traits of biocrusts. Plant Soil 406:131-143

Mallen-Cooper M, Eldridge DJ, Delgado-Baquerizo M (2018) Livestock grazing and aridity reduce the functional diversity of biocrusts. Plant Soil. https://doi.org/10.1007/s11104-0173388-5 (this issue)

Muñoz-Rojas M, Chilton A, Liyanage GS, Erickson TE, Merritt DJ, Neilan BA, Ooi MKJ (2018) Effects of indigenous soil cyanobacteria on seed germination and seedling growth of arid species used in restoration. Plant Soil. https://doi. org/10.1007/s11104-018-3607-8 (this issue)

Raggio J, Green TGA, Pintado A, Sancho L, Büdel B (2018) Environmental determinants of biocrust carbon fluxes across Europe: possibilities for a functional type approach. Plant Soil. https://doi.org/10.1007/s11104-018-3646-1 (this issue)

Reynolds R, Belnap J, Reheis M, Lamothe P, Luiszer F (2001) Aeolian dust in Colorado Plateua soils: nutrient inputs and recent change in source. Proc Nat Acad Sci 98:7123-7127

Rodríguez-Caballero E, Belnap J, Büdel B, Crutzen PJ, Andreae MO, Pöschl U, Weber B (2018) Dryland photoautotrophic soil surface communities endangered by global change. Nat Geosci 11:185-189

Rossi F, Mugnai G, De Phillipis R (2018) Complex role of the polymeric matrix in biological soil crusts. Plant Soil doi: https://doi.org/10.1007/s11104-017-3459-7 (this issue)

Rutherford WA, Painter TH, Ferrenberg S, Belnap J, Okin GS, Flagg C, Reed SC (2017) Albedo feedbacks to future climate via climate change impacts on dryland biocrusts. Sci Rep 7: 44188
Sancho LG, Maestre FT, Büdel B (2014) Biological soil crusts in a changing world: Introduction to the special issue. Biodivers Conserv 23:1611-1617

Scarlett NH (1994) Soil crusts, germination and weeds - issues to consider. Vic Nat 111:125-130

Sorochkina K, Ayuso SV, Garcia-Pichel F (2018) Establishing rates of lateral expansion of cyanobacterial biological soil crusts for optimal restoration. Plant Soil. https://doi. org/10.1007/s11104-018-3695-5 (this issue)

St. Clair LL, Johansen JR, Webb BL (1986) Rapid stabilization of fire-disturbed sites using a soil crust slurry: inoculation studies. Reclam Reveg Res 4:261-269

Strauss SL, Day TA, Garcia-Pichel F (2012) Nitrogen cycling in desert biological soil crusts across biogeographic regions in the Southwestern United States. Biogeochemistry 108:171-182

Steven B, Kuske CR, Gallegos-Graves LV, Reed SC, Belnap J (2015) Climate change and physical disturbance manipulations result in distinct biological soil crust communities. Appl Environ Microbiol 81:7448-7459

Su YG, Li XR, Zheng JG, Huang G (2009) The effect of biological soil crusts of different successional stages and conditions on the germination of seeds of three desert plants. J Arid Environ 73:931-936

Swenson T, Coradeau E, Bowen BP, De Philippis R, Rossi F, Mugnai G, Northen TR (2018) A novel method to evaluate nutrient retention by biological soil crust exopolymeric function. Plant Soil doi:https://doi.org/10.1007/s11104-0173537-x (this issue)

Tamm A, Caesar J, Kunz N, Colesie C, Reichenberger H, Weber B (2018) Ecophysiological properties of three biological soil crust types and their photoautotrophs from the Succulent Karoo. South Africa. Plant Soil. https://doi.org/10.1007 /s11104-018-3635-4 (this issue)

Torres-Cruz TJ, Howell AJ, Reibold RH, McHugh T, Eickhoff MA, Reed SC (2018) Species-specific nitrogenase activity in lichen-dominated biological soil crusts from the Colorado Plateau. USA. Plant Soil. https://doi.org/10.1007/s11104018-3580-2 (this issue)

Weber B, Büdel B, Belnap J (eds) (2016) Biological soil crusts: an organizing principle in drylands. Ecological Studies, vol 226. Springer, Cham

Whitford WG (2002) Ecology of Desert Systems. Academic Press, London

Zhang Y, Aradottir AL, Serpe M, Boeken B (2016) Interactions of Biological Soil Crusts with Vascular Plants. In: Weber B, Büdel B, Belnap J (eds) Biological soil crusts: an organizing principle in drylands. Springer, Cham, pp 385-406

Zhang Y, Duan P, Zhang P, Li M (2018) Variations in cyanobacterial and algal communities and soil characteristics under biocrust development under similar environmental conditions. Plant Soil. https://doi.org/10.1007/s11104-0173443-2 (this issue) 